\title{
Sleep Quality on Maintenance Hemodialysis Patients in Douala General Hospital in Cameroon
}

\section{Fouda Menye Ebana Hermine Danielle ${ }^{*}$, Maimouna Mahamat ${ }^{1}$, Kaze Folefack Francois ${ }^{1}$, Halle Marie-Patrice ${ }^{2}$, Ashuntantang Gloria ${ }^{1}$}

\author{
${ }^{1}$ Department of Internal Medicine, Faculty of Medicine and Biomedical Sciences of Yaoundé, Yaoundé, Cameroon \\ ${ }^{2}$ Department of Internal Medicine, Faculty of Medicine and Pharmaceutic Sciences of Douala, Douala, Cameroon \\ Email: *mendjouf@yahoo.fr
}

How to cite this paper: Danielle, F.M.E.H., Mahamat, M., Francois, K.F., Marie-Patrice, H. and Gloria, A. (2017) Sleep Quality on Maintenance Hemodialysis Patients in Douala General Hospital in Cameroon. Open Journal of Nephrology, 7, 61-68.

https://doi.org/10.4236/ojneph.2017.73008

Received: May 8, 2017

Accepted: August 21, 2017

Published: August 23, 2017

Copyright $\odot 2017$ by authors and Scientific Research Publishing Inc. This work is licensed under the Creative Commons Attribution International License (CC BY 4.0).

http://creativecommons.org/licenses/by/4.0/ (c) (i) Open Access

\begin{abstract}
Background: Poor sleep quality is reported to be common in hemodialysis patients. However, limited data are available about its prevalence in sub-Saharan region. The aim of this study was to assessed sleep quality and its predictors among hemodialysis patients. Methods: We conducted a cross sectional study of 2 weeks in the Douala General Hospital hemodialysis center of Cameroon involving 46 chronic hemodialyzed patients for at least six months with arteriovenous fistula. Quality of sleep was measured using the Pittsburgh Sleep Quality Index (PSQI) and laboratory data were collected in patients" fields. Result: Thirty-five (76.1\%) subjects reported poor sleep quality. The most frequent abnormal sleep components were subjective sleep quality, sleep disturbances and sleep latency ( $87 \%, 85 \%$ and $76 \%$ respectively). In univariate linear regression, hemoglobin level, sleep quality, sleep latency, sleep duration, habitual sleep efficiency and sleep disturbance were associated with poor sleep quality. In multivariate linear regression only hemoglobin level $(p=0.004)$ and sleep latency $(\mathrm{p}=0.002)$ were associated with poor sleep quality. Conclusion: Poor sleep quality is frequent in our hemodialysis patients and hemoglobin seems to be a good predictor of sleep quality in these patients.
\end{abstract}

\section{Keywords}

Sleep Quality, Hemodialysis, Cameroon, Anemia

\section{Introduction}

Sleep disorder is common in patients with end stage renal disease particularly on those undergoing dialysis therapies. It has been noted that $44 \%-80 \%$ of end 
stage renal disease (ESRD) patients reported sleep complaints [1] [2] [3]. Sleep disorder in this population is a severe comorbidity since it is associated with poor quality of life [4] [5] [6], depression [4], increasing systemic inflammation, cardio-vascular risk and mortality [6] [7] [8] [9]. Sleep disorder included a wide range of disorders such as insomnia, sleep-related breathing disorder, central disorder of hypersomnolence, sleep-related movement disorder, parasomnia and circadian rhythm sleep-wake disorder [10]. Most of them have been described in ESRD patients, but sleep apnea, restless leg syndrome, insomnia and excessive daytime somnolence are mainly found. Many risk factors have been associated to sleep disorder in ESRD patients, such as older age, dialysis shift (morning or night), anemia, hypoalbuminemia, high PTH and chronic pain [2] [6] [11]. However, limited data are available about sleep quality in dialysis patients in sub-Saharan countries such as Cameroon. Our aim was to assess sleep quality and its predictors in patients undergoing maintenance hemodialysis in the main hemodialysis service of the economic capital of Cameroon.

\section{Methodology}

We conducted a cross sectional study of 2 weeks from 5 to 17 September 2016 in the Douala General Hospital hemodialysis center of Cameroon. Only patient on maintenance hemodialysis of more than 6 months with arteriovenous fistula were included. Quality of sleep was measured using the Pittsburgh Sleep Quality Index (PSQI). The PSQI [12] evaluates the attitude of patients about their quality of sleep in the past 4 weeks. It contains 19 self-rated questions and 5 questions rated by the roommate. The 19 self-rate questions are combined to form 7 components scores: quality of sleep, delay in falling asleep (sleep latency), effective duration of sleep, sleep efficacy, sleep disorders, needed amount of sleep-inducing pills, and daytime performance. Each component score has a range of 0 - 3 points. In all case, a score of " 0 " indicate no difficulty while a score of " 3 " indicate severe difficulty. The 7 components scores are add to yield a global PSQI score with a range of 0 to 21 points; higher scores indicate lower quality of sleep. A global PSQI score greater than 5 indicates poor sleep quality. Roommate answers can also be scoring 0 - 3 points according to the severity of the symptom, but they are not included in the global PSQI score.

PSQI Questionnaire was self-administrated by the patient at home and laboratory data were collected in patient's fields (serum calcium and phosphate, hemoglobin level). Socio-demographic data was also collected (age, dialysis vintage, employment) as well as comorbidities such as diabetes and HIV status.

Patients were also asked to complete the hospital anxiety and depression scale (HADS). HADS [13] is a brief and widely used measure of psychological distress in outpatient setting. The HADS contains 14 items and consists of two sub scales of anxiety and depression. Each item is rated on a 4-point scale, giving a maximum score of 21 for each of the anxiety and depression sub scales. Scores of 11 or more on either sub scale are considered to be a significant "case" of psycho- 
logical morbidity, while scores of 8 - 10 represents a "borderline" and 0 - 7 a "normal" case.

The study was approved by the ethics committee of the General Hospital of Douala. Patient information was collected and his/her consent was obtained as required by the ethics committee.

Data were summarized as mean ( \pm standard deviation) and frequency (percentage). Comparison of demographic factors, medical profiles, biochemical factor among good and poor sleepers was done with Fisher's exact or chi-square test. Pearson's correlation and linear regression were used to assess the relationship between variables and sleep disturbance. Data were analyzed using the SPSS software version 20.0 (SPSS, Chicago, Illinois, USA). The significance level was considered to be $\mathrm{p}<0.05$ throughout the study.

\section{Results}

A total of 46 (54.4\% females) participants were included among which $74 \%$ were unemployed. Their mean age was $44.01 \pm 4.8$ years and median dialysis duration was 2 years (6 months to 9 years). Diabetes mellitus (22\%) and HIV infection (12\%) were the main comorbidities. The mean serum calcium and hemoglobin was $2.27 \pm 0.25 \mathrm{mmol} / \mathrm{l}$ and $8.07 \pm 1.96 \mathrm{~g} / \mathrm{dl}$ respectively; the prevalence of severe anemia (hemoglobin $<8 \mathrm{~g} / \mathrm{dl}$ ) was $37 \%$. The PSQI ranged from $0-18$ with a median score of 7 . Thirty five (76.1\%) participants reported poor sleep quality. The most frequent abnormal sleep components were subjective sleep quality (87\%), sleep disturbances (85\%) and sleep latency (76\%, Table 1). Mean sleep duration was $6.75 \pm 2.5$ hours with 13 patients (28\%) slept less than 5 hours per night. Mean sleep latency was $41 \pm 43.45$ minutes. Age, sex, dialysis vintage, diabetes, HIV, employment and serum calcium was not associated with poor sleep quality (Table 2). Hemoglobin was negatively correlated with poor sleep quality $(r=$

Table 1. PSQI component scores.

\begin{tabular}{|c|c|c|c|c|}
\hline $\begin{array}{l}\text { Sleep component } \\
\qquad(\mathrm{n}=46)\end{array}$ & $\begin{array}{l}\text { Never } \\
\mathrm{n}(\%)\end{array}$ & $\begin{array}{c}\text { Less than once } \\
\text { per week } \\
\mathrm{n}(\%)\end{array}$ & $\begin{array}{c}\text { Once or twice } \\
\text { per week } \\
\mathrm{n}(\%)\end{array}$ & $\begin{array}{c}\text { Three or more } \\
\text { per week } \\
\mathrm{n}(\%)\end{array}$ \\
\hline Subjective sleep quality & $6(13)$ & $21(46)$ & $11(24)$ & $8(17)$ \\
\hline Sleep latency & $11(24)$ & $8(17)$ & $13(28)$ & $14(31)$ \\
\hline Sleep duration & $19(41)$ & $9(20)$ & $5(11)$ & $13(28)$ \\
\hline $\begin{array}{l}\text { Habitual sleep } \\
\text { efficiency }\end{array}$ & $21(46)$ & $5(10)$ & $6(13)$ & $14(31)$ \\
\hline Sleep disturbance & $7(15)$ & $19(42)$ & $17(36.5)$ & $3(6.5)$ \\
\hline $\begin{array}{l}\text { Daytime } \\
\text { dysfunction }\end{array}$ & $16(35)$ & $13(28$ & $11(24)$ & $6(13)$ \\
\hline Sleep medication & $39(83.5)$ & $3(6.5)$ & $2(4.5)$ & $2(4.5)$ \\
\hline $\begin{array}{l}\text { Loud snoring or long } \\
\text { breath pauses }\end{array}$ & $28(61)$ & $1(2)$ & $4(9)$ & $15(28)$ \\
\hline Leg twitching or jerking & $33(72)$ & $3(6.5)$ & $3(6.5)$ & $7(15)$ \\
\hline
\end{tabular}


Table 2. Comparison of different factors between good and poor sleepers.

\begin{tabular}{|c|c|c|c|c|c|}
\hline & & Number (\%) & Means PSQI & $\begin{array}{c}\text { Poor } \\
\text { sleepers n (\%) }\end{array}$ & $P$ value \\
\hline \multirow{4}{*}{ Age (years) } & $<20$ & $9(19.5)$ & $6.44 \pm 5.43$ & $6(67)$ & \multirow{4}{*}{0.904} \\
\hline & $20-40$ & $10(22)$ & $9.2 \pm 4.98$ & $8(80)$ & \\
\hline & $41-60$ & $18(39)$ & $8.77 \pm 3.87$ & $14(78)$ & \\
\hline & $>60$ & $9(19.5)$ & $9.33 \pm 4.81$ & $7(78)$ & \\
\hline \multirow{2}{*}{ Sex } & Female & $25(54.4)$ & $7.88 \pm 4.83$ & $19(76)$ & \multirow{2}{*}{0.631} \\
\hline & Male & $21(45.6)$ & $9.28 \pm 4.78$ & $16(76)$ & \\
\hline \multirow{2}{*}{ diabetes } & yes & $10(22)$ & $8.3 \pm 4.16$ & $7(70)$ & \multirow{2}{*}{0.447} \\
\hline & no & $36(78)$ & $9.3 \pm 6.11$ & $28(78)$ & \\
\hline \multirow{2}{*}{ HIV } & yes & $5(12)$ & $7 \pm 4.79$ & $3(60)$ & \multirow{2}{*}{0.343} \\
\hline & no & $41(88)$ & $8.7 \pm 4.83$ & $32(78)$ & \\
\hline \multirow{2}{*}{ Employment } & yes & $12(26)$ & $7.66 \pm 3.54$ & $15(72)$ & \multirow{2}{*}{0.369} \\
\hline & no & $34(74)$ & $9.24 \pm 5.63$ & $25(80)$ & \\
\hline \multirow{3}{*}{$\begin{array}{l}\text { Dialysis vintage } \\
\text { (months) }\end{array}$} & $<12$ & $17(37)$ & $8.17 \pm 5.73$ & $12(71)$ & \multirow{3}{*}{0.415} \\
\hline & $12-60$ & $18(39)$ & $7.7 \pm 4.56$ & $13(72)$ & \\
\hline & $>60$ & $11(24)$ & $10.36 \pm 3.32$ & $10(91)$ & \\
\hline \multirow{3}{*}{$\begin{array}{l}\text { Calcium* } \\
(\mathrm{mmol} / \mathrm{l})\end{array}$} & $\leq 2.1$ & $6(20)$ & $10 \pm 4.38$ & $5(84)$ & \multirow{3}{*}{0.264} \\
\hline & $2.2-2.7$ & $22(73)$ & $8.09 \pm 5.36$ & $15(68)$ & \\
\hline & $\geq 2.8$ & $2(7)$ & $14 \pm 4.24$ & $2(100)$ & \\
\hline \multirow{3}{*}{$\begin{array}{l}\text { Hemoglobin** } \\
\text { (g/dl) }\end{array}$} & $>10$ & $9(23)$ & $6.66 \pm 5.38$ & $4(45)$ & \multirow{3}{*}{0.004} \\
\hline & $8-10$ & $13(33)$ & $9.07 \pm 4.9$ & $10(77)$ & \\
\hline & $<8$ & $17(44)$ & $10.47 \pm 4.22$ & $17(100)$ & \\
\hline
\end{tabular}

*available for 30 patients; ${ }^{* *}$ available for 39 patients.

$-0.529 \mathrm{p}=0.001)$, PSQI global score $(\mathrm{r}=-0.329 \mathrm{p}=0.021)$, habitual sleep efficiency $(-332, \mathrm{p}=0.039)$ and sleep disturbance $(\mathrm{r}=-0.369, \mathrm{p}=0.021$, Table 3$)$. Anxiety was associated with sleep duration $(r=0.403, \mathrm{p}=0.006)$ and PSQI global score $(\mathrm{r}=0.361, \mathrm{p}=0.014)$; unemployment with sleep medication $(\mathrm{r}=-0.301$, $\mathrm{p}=0.044)$ and leg twitching/jerking $(\mathrm{r}=-0.328, \mathrm{p}=0.028)$ and hypocalcemia with daytime dysfunction $(r=0.400, p=0.028)$. In univariate linear regression, hemoglobin level $(p=0.001)$, sleep quality $(p<0.001)$, sleep latency $(p<0.001)$, sleep duration $(\mathrm{p}=0.02)$, habitual sleep efficiency $(\mathrm{p}<0.001)$ and sleep disturbance $(\mathrm{p}=0.013)$ were associated with poor sleep quality. In multivariate linear regression only hemoglobin level $(\mathrm{p}=0.004)$ and sleep latency $(\mathrm{p}=0.002)$ was associated with poor sleep quality.

\section{Discussion}

This study shows that poor sleep quality is common in our hemodialysis patients 
Table 3. Predictors of PSQI global score and PSQI sleep component.

\begin{tabular}{|c|c|c|c|}
\hline & & Pearson's $r$ & $P$ value \\
\hline \multirow{10}{*}{ Total PSQI score } & Hemoglobin & -0.369 & 0.021 \\
\hline & Subjective sleep quality & 0.820 & $<0.001$ \\
\hline & Sleep latency & 0.759 & $<0.001$ \\
\hline & Sleep duration & 0.718 & $<0.001$ \\
\hline & Sleep efficiency & 0.815 & $<0.001$ \\
\hline & Sleep medication & 0.349 & 0.019 \\
\hline & Sleep disturbance & 0.565 & $<0.001$ \\
\hline & Daytime dysfunction & 0.395 & 0.006 \\
\hline & Leg twitching or jerking & 0.297 & 0.047 \\
\hline & Anxiety & 0.361 & 0.014 \\
\hline \multirow{4}{*}{$\begin{array}{c}\text { Subjective sleep } \\
\text { quality }\end{array}$} & Sleep latency & 0.580 & $<0.001$ \\
\hline & Sleep duration & 0.495 & $<0.001$ \\
\hline & Sleep efficiency & 0.609 & $<0.001$ \\
\hline & Sleep disturbance & 0.511 & $<0.001$ \\
\hline \multirow{3}{*}{ Sleep latency } & Sleep duration & 0.455 & 0.02 \\
\hline & Sleep efficiency & 0.585 & $<0.001$ \\
\hline & Sleep disturbance & 0.560 & 0.001 \\
\hline \multirow{2}{*}{ Sleep duration } & Sleep efficiency & 0.705 & $<0.001$ \\
\hline & Anxiety & 0.403 & 0.006 \\
\hline \multirow{2}{*}{$\begin{array}{c}\text { Habitual Sleep } \\
\text { efficiency }\end{array}$} & Hemoglobin & -0.332 & 0.039 \\
\hline & Sleep disturbance & 0.335 & 0.023 \\
\hline \multirow{2}{*}{ Sleep medication } & Employment & -0.301 & 0.044 \\
\hline & Depression & 0.326 & 0.019 \\
\hline \multirow{3}{*}{ Sleep disturbance } & Sex (male) & 0.306 & 0.039 \\
\hline & hemoglobin & -0.369 & 0.021 \\
\hline & $\begin{array}{l}\text { Loud snoring or long } \\
\text { breath pauses }\end{array}$ & 0.303 & 0.041 \\
\hline Daytime dysfunction & Calcium serum & -0.40 & 0.028 \\
\hline $\begin{array}{l}\text { Loud snoring or long } \\
\text { breath pauses }\end{array}$ & Leg twitching or jerking & 0.317 & 0.034 \\
\hline $\begin{array}{l}\text { Leg twitching } \\
\text { or jerking }\end{array}$ & Employment & -0.328 & 0.028 \\
\hline
\end{tabular}

and that correction of anemia could improve sleep quality particularly sleep efficiency and sleep disturbance components. Sleep duration was also associated with anxiety.

Prevalence of poor sleep quality in our study is similar to previous reported study in developing countries [2] [14] [15] as well as in developed countries [3] [4] [16]. Using the same sleep measure instrument (PSQI), prevalence of poor sleep quality ranges from $57 \%$ to $91 \%$ [4] [15] [16] [17] [18]. The reason of this 
high prevalence of poor sleep quality in ESRD patient is poorly understood and probably multifactorial. Sympathetic hyperactivity, decrease vagal tone, decrease in nocturnal release of melatonin-a hormone responsible for the sleep-wake circadian rhythm and psychological factors have been underlined as pathophysiological mechanisms [19] [20].

Insomnia is the most reported sleep disorder in hemodialysis patients. The most important symptoms are difficulty in initiation of sleep, difficulty in sleep maintenance, falling back to sleep after nocturnal awakenings and spontaneous early awakenings, which can be accessed through sleep disturbance, sleep latency and sleep duration PSQI component. As sleep disturbance and sleep latency was very frequent ( $85 \%$ and $76 \%$ respectively), insomnia is probably very common in our patients. Insomnia has been associated with older age, chronic pain, stress, dialysis shift and high level of parathyroid hormone [6] [11] [21]. We found that sleep disturbance was associated with male sex and hemoglobin level.

Polysomnography studies have showed that ESRD patient had poor sleep architecture [21]. They have short and fragmented sleep with total sleep times between 260 - $360 \mathrm{~min}$, low sleep efficiency (66\% - 85\%), long sleep latency (10 - 30 $\mathrm{min}$ ) and rapid eye movement latency (92 - $64 \mathrm{~min})$. Although it has been recognized that the PSQI may not always be associated with polysomnographic findings of a distinct primary sleep disorder, we noted in our study that third patient had sleep efficiency $<65 \%$, third a sleep latency $>30$ min and another third slept less than 5 hours per night. Interesting, sleep duration was associated with anxiety and sleep efficiency with hemoglobin level. Indeed, previous investigators have reported the strong association of PSQI scores to depression, psychosocial stress and hemoglobin level [4] [22] [23].

Many predictors of poor sleep quality in ESRD patient have been suggested; included employment status, depression, anxiety, older age, hemoglobin level and being in hemodialysis rather than peritoneal dialysis [15] [16] [17] [23]. In our study, male sex, employment, hemoglobin level, serum calcium, anxiety and depression were associated with PSQI sleep component; hemoglobin and anxiety were associated with total PSQI score. However only hemoglobin was associated to poor sleep quality in univariate and multivariate regression. Correction of anemia may then improve sleep quality in our setting.

This study had several limitations. First, this was a cross-sectional study and no cause and effect relationships between the studied parameters and quality of sleep can be established. Second, our study population is small and our result may not be representative of the overall Cameroonian hemodialysis population. Third, we did not perform polysomnographic and assessed sleep quality only subjectively. Future studies should consider these limitations.

\section{Conclusion}

Poor sleep quality is frequent in our hemodialysis patients and it is associated with hemoglobin level and anxiety. Since poor sleep quality has been generally 
underdiagnosed but have great impact on life quality and mortality, effort should be done for detection and intervention. This study also indicates that correction of anemia may improve sleep quality in our setting.

\section{Acknowledgements}

The authors wish to thank DrEbana Steve and Ms Marie Effa for their assistance in designing the study and data collection.

\section{Conflict of Interest}

Authors declare no conflict of interest.

\section{References}

[1] Murtagh, F.E., Addington-Hall, J. and Higginson, I.J. (2007) The Prevalence of Symptom in End-Stage Renal Disease: A Systematic Review. Advances in Chronic Kidney Disease, 14, 82-99. https://doi.org/10.1053/j.ackd.2006.10.001

[2] Sabry, A.A., Abo-Zenah, H., Wafa, E., Mahmoud, K., El-Dahshan, K., Hassan, A., Abbas, T.M., Saleh, A.B. and Okasha, K. (2010) Sleep Disorders in Hemodialysis Patients. Saudi Journal of Kidney Diseases and Transplantation, 21, 300-305.

[3] Merlino, G., Piani, A., Dolso, P., Adorati, M., Cancelli, I., Valente, M. and Gigli, G.L. (2006) Sleep Disorders in Patients with End-Stage Renal Disease Undergoing Dialysis Therapy. Nephrology Dialysis Transplantation, 21, 184-190.

https://doi.org/10.1093/ndt/gfil44

[4] Iliescu, E.A., Coo, H., McMurray, M.H., Meers, C.L., Quinn, M.M., Singer, M.A. and Hopman, W.M. (2003) Quality of Sleep and Health-Related Quality of Life in Haemodialysis Patients. Nephrology Dialysis Transplantation, 18, 126-132.

https://doi.org/10.1093/ndt/18.1.126

[5] Mucsi, I., Molnar, M.Z., Ambrus, C., Szeifert, L., Kovacs, A.Z., Zoller, R., Barótfi, S., Remport, A. and Novak, M. (2005) Restless Legs Syndrome, Insomnia and Quality of Life in Patients on Maintenance Dialysis. Nephrology Dialysis Transplantation, 20, 571-577. https://doi.org/10.1093/ndt/gfh654

[6] Elder, S.J., Pisoni, R.L., Akizawa, T., Fissell, R., Andreucci, V.E., Fukuhara, S., Kurokawa, K., Rayner, H.C., Furniss, A.L., Port, F.K. and Saran, R. (2008) Sleep Quality Predicts Quality of Life and Mortality Risk in Haemodialysis Patients: Results from the Dialysis Outcomes and Practice Patterns Study (DOPPS). Nephrology Dialysis Transplantation, 23, 998-1004. https://doi.org/10.1093/ndt/gfm630

[7] Chiu, Y.L., Chuang, Y.F., Fang, K.C., et al. (2009) Higher Systemic Inflammation Is Associated with Poorer Sleep Quality in Stable Haemodialysis Patients. Nephrology Dialysis Transplantation, 24, 247-251. https://doi.org/10.1093/ndt/gfn439

[8] Mallon, L., Broman, J.E. and Hetta, J. (2002) Sleep Complaints Predict Coronary Artery Disease Mortality in Males: A 12-Year Follow-Up Study of a Middle-Aged Swedish Population. Journal of Internal Medicine, 251, 207-216.

https://doi.org/10.1046/j.1365-2796.2002.00941.x

[9] Benz, R.L., Pressman, M.R., Hovick, E.T. and Peterson, D.D. (2000) Potential Novel Predictors of Mortality in End-Stage Renal Disease Patients with Sleep Disorders. American Journal of Kidney Diseases, 35, 1052-1060. https://doi.org/10.1016/S0272-6386(00)70039-4

[10] American Academy of Sleep Medicine (2014) International Classification of Sleep 
Disorders. 3rd Edition, American Academy of Sleep Medicine, Darien.

[11] Sabbatini, M., Minale, B., Crispo, A., Pisani, A., Ragosta, A., Esposito, R., Cesaro, A., Cianciaruso, B. and Andreucci, V.E. (2002) Insomnia in Maintenance Haemodialysis Patients. Nephrology Dialysis Transplantation, 17, 852-856.

https://doi.org/10.1093/ndt/17.5.852

[12] Buysse, D.J., Reynolds, C.F., Monk, T.H., Berman, S.R. and Kupfer, D.J. (1989) The Pittsburgh Sleep Quality Index (PSQI): A New Instrument for Psychiatric Research and Practice. Psychiatry Research, 28, 193-213. https://doi.org/10.1016/0165-1781(89)90047-4

[13] Zigmond, A.S. and Snaith, R.P. (1983) The Hospital Anxiety and Depression Scale. Acta Psychiatrica Scandinavica, 67, 361-370. https://doi.org/10.1111/j.1600-0447.1983.tb09716.x

[14] Chen, W.C., Lim, P.S., Wu, W.C., Chiu, H.C., Chen, C.H., Kuo, H.Y., Tsai, T.W., Chien, P.I., Su, Y.J., Su, Y.L., Hung, S.H. and Woods, H.F. (2006) Sleep Behavior Disorders in a Large Cohort of Chinese (Taiwanese) Patients Maintained by LongTerm Hemodialysis. American Journal of Kidney Diseases, 48, 277-284. https://doi.org/10.1053/j.ajkd.2006.04.079

[15] Araujo, S.M., Bruin, V.M., Daher, E.F., Medeiros, C.A., Almeida, G.H. and Bruin, P.F. (2011) Quality of Sleep and Day-Time Sleepiness in Chronic Hemodialysis: A Study of 400 Patients. Scandinavian Journal of Urology, 45, 359-364. https://doi.org/10.3109/00365599.2011.584694

[16] Masoumi, M., Naini, A.E., Aghaghazvini, R., Amra, B. and Gholamrezaei, A. (2013) Sleep Quality in Patients on Maintenance Hemodialysis and Peritoneal Dialysis. International Journal of Preventive Medicine, 4, 165-172.

[17] Guney, I., Atalay, H., Solak, Y., Altintepe, L., Toy, H., Tonbul, H.Z. and Turk, S. (2010) Predictors of Sleep Quality in Hemodialysis Patients. International Journal of Artificial Organs, 33, 154-160.

[18] Mehrabi, S., Sarikhani, S. and Roozbeh, J. (2017) Sleep Quality in Patients Undergoing Long-Term Hemodialysis Using the Pittsburgh Sleep Quality Index. NephroUrology Monthly, 9, Article ID: e44278. https://doi.org/10.5812/numonthly.44278 http://numonthly.com/?page=article\&article id $=44278$

[19] Neumann, J., Ligtenberg, G., Klein, I.I., Koomans, H.A. and Blankestijn, P.J. (2004) Sympathetic Hyperactivity in Chronic Kidney Disease: Pathogenesis, Clinical Relevance, and Treatment. Kidney International, 65, 1568-1576. https://doi.org/10.1111/j.1523-1755.2004.00552.x

[20] Mehta, R. and Drawz, P.E. (2011) Is Nocturnal Blood Pressure Reduction the Secret to Reducing the Rate of Progression of Hypertensive Chronic Kidney Disease? Current Hypertension Reports, 13, 378-385. https://doi.org/10.1007/s11906-011-0217-8

[21] Maung, S.C., El Sara, A., Chapman, C., Cohen, D. and Cukor, D. (2016) Sleep Disorders and Chronic Kidney Disease. World Journal of Nephrology, 5, 224-232. https://doi.org/10.5527/wjn.v5.i3.224

[22] Selvi, Y., Aydin, A., Boysan, M., Atli, A., Agargun, M.Y. and Besiroglu, L. (2010) Associations between Chronotype, Sleep Quality, Suicidality, and Depressive Symptoms in Patients with Major Depression and Healthy Controls. Chronobiology International, 27, 1813-1828. https://doi.org/10.3109/07420528.2010.516380

[23] Pai, M.F., Hsu, S.P., Yang, S.Y., Ho, T.I., Lai, C.F. and Peng, Y.S. (2007) Sleep Disturbance in Chronic Hemodialysis Patients: The Impact of Depression and Anemia. Renal Failure, 29, 673-677. https://doi.org/10.1080/08860220701459642 
Submit or recommend next manuscript to SCIRP and we will provide best service for you:

Accepting pre-submission inquiries through Email, Facebook, LinkedIn, Twitter, etc. A wide selection of journals (inclusive of 9 subjects, more than 200 journals)

Providing 24-hour high-quality service

User-friendly online submission system

Fair and swift peer-review system

Efficient typesetting and proofreading procedure

Display of the result of downloads and visits, as well as the number of cited articles Maximum dissemination of your research work

Submit your manuscript at: http://papersubmission.scirp.org/

Or contact ojneph@scirp.org 